\title{
The Effect of Laser Welding on the Ten- sile Strength and Radiographic Analysis of Co-Cr Repaired Joints
}

Nadira A Hatim

BDS, MSc (Prof.)

Nazar Gh Jameel BDS, MSc (Asst. Prof)

Abdullah J Mohammed BDS, MSc (Asst.Lec)
Dept of Prosthodontics

College of Dentistry, University of Mosul

Dept of Oral and maxillofacial surgery College of Dentistry, University of Mosul

Dept of Prosthodontics

College of Dentistry, University of Mosul

$$
\begin{aligned}
& \text { الخلاصة } \\
& \text { الاهداف: لتقييم تأثير اللحام بواسطة الليزر و القوس الكهر بائي على قوة الشد و والمظهر الإشعاعي لمفاصل سبيكة الكوبلت كروم المرمة. فضلا عن دراسة }
\end{aligned}
$$

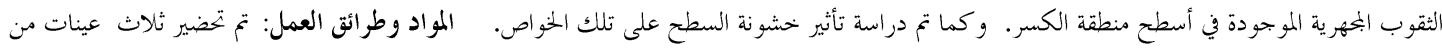

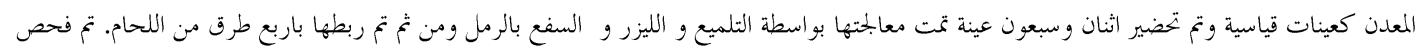

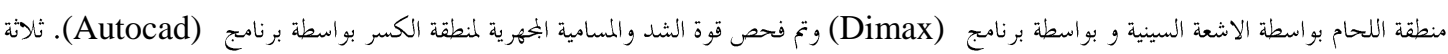

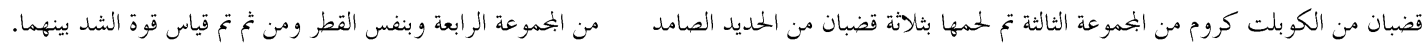

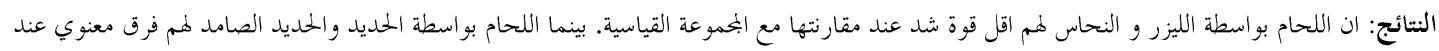

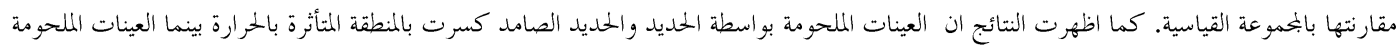

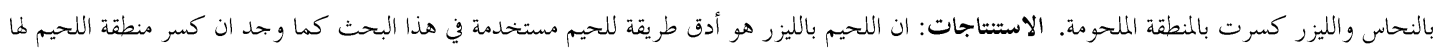

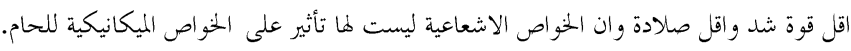

\begin{abstract}
Aims: To evaluate the effect of laser welding and arc welding on the ultimate tensile strength, radiographic appearance of the joints, and microscopic porosities in the fractographs. Four joining methods have been used, laser welding, and arc welding using three types of electrodes (iron, stainless steel, and brass). Effect of surface roughness on the aforementioned properties was evaluated. Materials and Methods: Three specimens as-cast control group, seventy two specimens were treated by polishing, laser, and sandblasting, and joined with the four joining methods. Joints examined by radiograph and porosities were measured by Dimax software program, their ultimate tensile strength, and strain was tested, and the microscopic porosities in the fractographs were measured using AutoCAD software program. Three cobalt chromium bars from the third group were joined to three stainless steel bars from the fourth group of the same diameter to test the ultimate tensile strength, and strain of the dissimilar alloys. Results: Laser welded and brass soldered joints had significantly lower ultimate tensile strength and strain when compared to the control group, while the iron, and stainless steel soldered joints had insignificant differences in the ultimate tensile strength and strain when compared to the control group. Results shown that the iron and stainless steel soldered samples fractured in the heat affected zone while the brass soldered and laser welded samples fractured in the weld zone. The iron and stainless steel soldered joints had superior mechanical properties when compared with the control group. Laser welding of dissimilar alloys had the lowest mechanical properties among all techniques. Conclusions: revealed that laser welding was the most precise technique used in the current study. Weld fractures shown less tensile strength average and more brittle behavior. Radiographic properties had no influence on the mechanical properties of the joints.

Key words: Laser welding, Bracing materials, Cr-Co.

$\overline{\text { Hatim NA, Jameel N Gh, Mohammed AJ. The Effect of Laser Welding on the Tensile Strength and }}$ Radiographic Analysis of Co-Cr Repaired Joints. Al-Rafidain Dent J. 2012; 12(1): 1-13.

Received: 28/12/2009 Sent to Referees: 31/12/2009 Accepted for Publication: 22/2/2010
\end{abstract}

\section{INTRODUCTION}

Cobalt-chromium casting alloys became available for cast removable par- tial-denture restorations; they have continued to increase in popularity. It was estimated as early as 1949 that more than 
$80 \%$ of all partial-denture appliances were cast from cobalt-chromium alloys. ${ }^{(1)}$ Clasps and connectors made of $\mathrm{Co}-\mathrm{Cr}$ often fatigue and fracture from repeated insertion/withdrawal movements and masticatory loading. Broken frameworks may be repaired by connecting broken pieces, or in the case of a lost piece, by fabricating that piece with a similar or different alloy and connecting it to the framework. ${ }^{(2)}$ Porosity, loss of alloying elements and, for some heat treatable aluminum alloys, solidification cracking are the most common problems encountered in the laser welding of these alloys. ${ }^{(3)}$

Standards designed to impart weld quality may differ from job to job, but the use of appropriate examination techniques can provide assurance that the applicable standards are being met. Nondestructive examination (NDE) methods of inspection make it possible to verify compliance to the standards on an ongo-

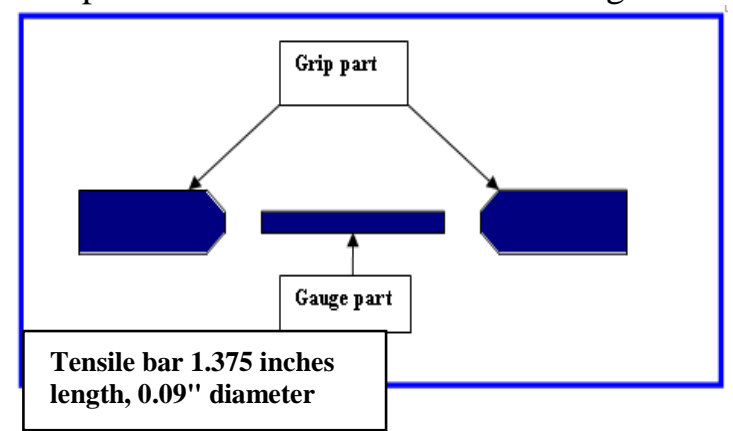

ing basis by examining the surface and subsurface of the weld and surrounding base material. The growing use of computerization with some methods provides added image enhancement, and allows real-time or near real-time viewing, comparative inspections and archival capabilities. A review of each method will help in deciding which process or combination of processes to use for a specific job and in performing the examination most effectively. ${ }^{(4)}$

\section{MATERIALS AND METHODS}

Samples were designed by using plastic spacer $2.5 \mathrm{~mm}$ gauge (Imprelon, Scheu/dental, Germany)dumbbell shaped according to ADA specification No.14. ${ }^{(5)}$

Group 1: The control group which consists of three samples, Every sample made of $0.09 " \pm 0.01 "$ gauge and $1.375 \pm 0.01$ inches, Figure (1).

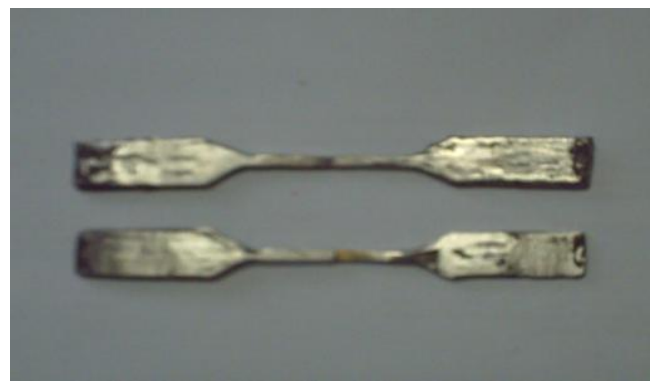

Figure (1): Illustrates the control group's two grip parts joining the tensile bar from the two side

Group 2: Thirty six half dumbbell shaped samples were constructed with blue casting wax (Plastodent-set, Degussa, Germany) with $0.09 " \pm 0.01 "$ gauge of the bar and $(0.687 \pm 0.01$ inches $)$ length, (Figure 2). The samples were divided into 3 subgroups:
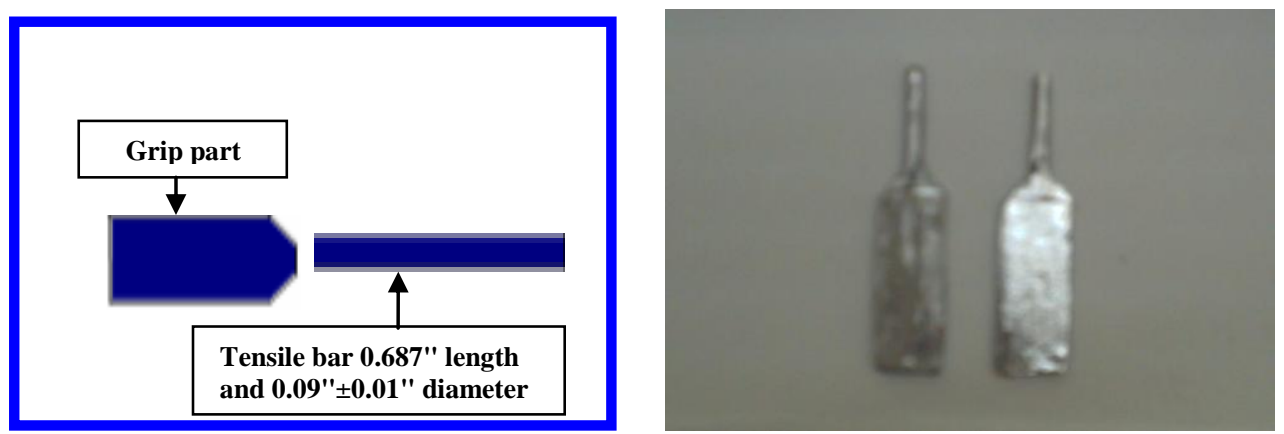

Figure (2): Illustrates the grip part and the tensile bar of the second group 
Subgroup A: Twelve samples which were sandblasted and polished with rubber discs. Subgroup B: Twelve samples were polished and with aluminum oxide $50 \mu \mathrm{m}$ grain size using (Perstrahl, Degussa, Germany; with Dental-Air compressor, Italy) for 30 seconds for each sample, using metal jig according to Hofstede et al ${ }^{(6)}$ to hold the sample's surface at constant dis- tance $(1 \mathrm{~cm})$ from the nozzle of the sandblasting machine. Subgroup C: Twelve samples were treated after polishing with diode laser using, (diode laser 1064, Fox, Germany) with the following parameters: $(1064 \mathrm{~nm}, 8 \mathrm{Watt}$, continuous wave) for 30 seconds for each sample, (Figure3)

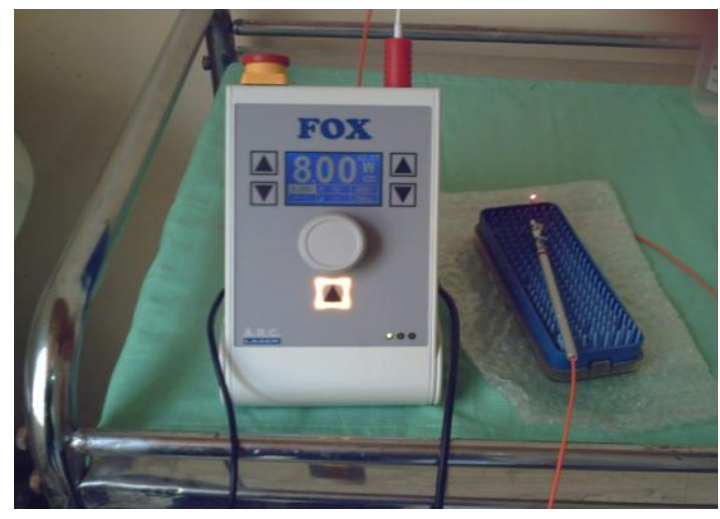

Figure (3): Diode laser 1064nm, Fox.

Three samples from each of subgroup (A, B, and C) were tested by profilemeter (Tylor-Hobson, England) to find the difference in surface roughness between the three treatment methods.

Laser Welding Process: Six samples of each of subgroup $\mathrm{A}, \mathrm{B}$, and $\mathrm{C}$ were selected randomly, every two samples from the same subgroup were perfectly aligned in a butt joint configuration. The welding parameters of power and pulse duration were performed using the following formula $^{(7)}: \mathrm{E}(\mathrm{J})=\mathrm{P}(\mathrm{kw}) \times \mathrm{t}(\mathrm{ms}) \mathrm{E}$ : is the energy used, $P$ : is the power, $t$ : is the pulse duration.

The samples were welded using NdYAG laser (Trumpf, HL 124P LCU, Germany), and using the following parameters: Repetition rate: $1 \mathrm{~Hz}$, Pulse energy: 14 , Peak power: $1 \mathrm{kw}$, Spot overlap: $80 \%$, Pulse duration: $14 \mathrm{~ms}$, Wave length: $1064 \mathrm{~nm}$ and Spot diameter: $0.5 \mathrm{~mm}$.

Arc Welding Processes: When the alignment process were achieved successfully by using a surveyor (Gerdent, Syria), the samples were soldered using an electric arc welding machine (BOC, England) and using the following parameters: $30 \mathrm{~A}$
D.C current and Power: 30V. Double bead technique were used according to American iron and steel institute, ${ }^{(8)}$ the electrode was held perpendicular to the long axis of the gauge to be soldered, single point soldering is made on one surface and then the sample is removed and turned upside down and another point is dropped on the opposite surface of the first point.

This process is achieved using Stainless steel electrodes 2mm-gauge (Kobelco, Japan) to solder six pieces of each of subgroup $\mathrm{A}, \mathrm{B}$, and $\mathrm{C}$, to make three dumbbell shaped samples.

Radiographic Analysis: All the samples (control, laser welded, soldered) were radio graphed using digital dental radiographic machine (Planmeca, Finland) operated at $8 \mathrm{~mA}, 70 \mathrm{kVp}$ and $0.12 \mathrm{sec}$. with the Dimax program software. The intraoral size-2 digital sensor of the X-ray machine was adapted to ensure parallelism with the floor. Then the samples were put on the sensor using a reference point. The $\mathrm{x}$-ray tube was aligned perpendicular to the gauge axis, and the x-ray beam was allowed to hit the sample (Figure 4) 


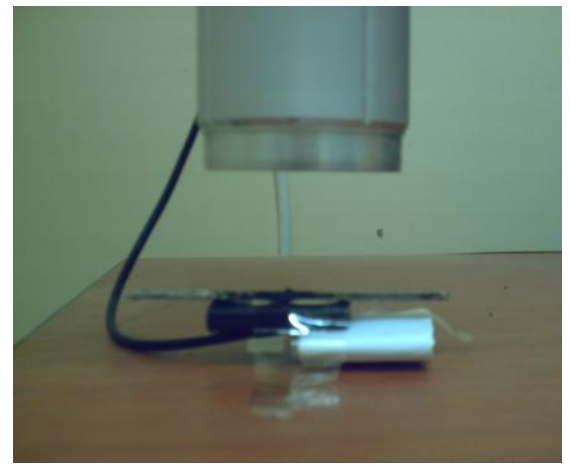

Figure (4): Planmeca digital X-ray machine

The resultant image were processed using Planmeca computer program, using the image processing options like contrast magnification X3, and reverse gray scale to find the most appropriate image to be analyzed.

The area of the porosities were measured using (HGIC) method: ${ }^{(9)}$ A-Find point at/or near the center. B-Drawing ra- diuses that extends to the perimeter of the irregular circle at 20 degrees intervals ( $\underline{r}$ ). $\mathrm{C}$-Measure the radius at 20 degrees intervals then the mean of the located radiuses (Figure 5) is used in the following formula: From the area of regular circle, Area $=\pi \mathrm{r}$ (Area of the irregular circle $=$ $\pi \underline{\mathbf{r}})^{(10)}$

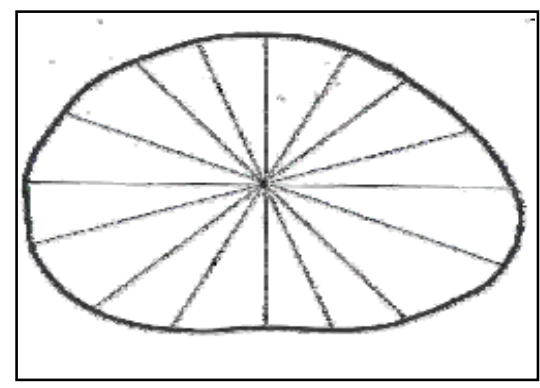

Figure (5): Record measurements to the nearest point, from the edge of the area to the center of the circle every 20 degrees. (HGIC,2005)

The sample's width was used for calibration of the image magnification. The width in image were divided by the original width $(2.5 \mathrm{~mm})$ to find the magnification power, then the area of the porosity were divided by the same magnification factor, (Figure 6).

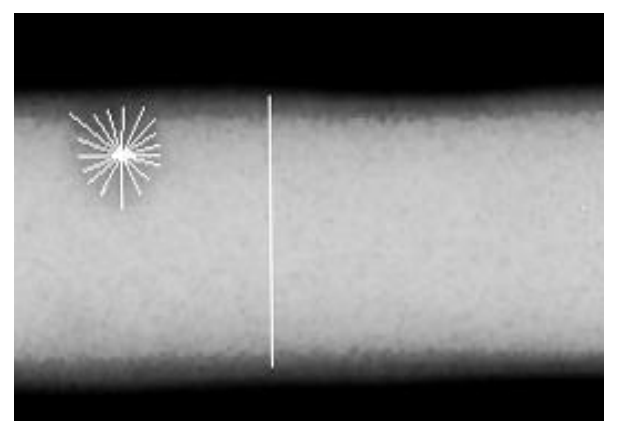

Figure (6): Measuring the area of irregular porosity in the radiographic image by Dimax program 
Ultimate Tensile Strength Test: The samples were tested by a universal testing machine (Amsler, Switzerland) at crosshead speed of $0.9 \mathrm{~mm} / \mathrm{sec}$. Failure load and elongation (\%) was recorded. Failure load were divided by the cross section area.

UTS $(\mathrm{Mpa})=$ Fracture load $(\mathrm{N}) /$ cross section area $\left(\mathrm{m}^{2}\right)^{(11)}$

Microscopic Inspection: The ruptured joints were separated from the grip part byusing cutting disks and fixed by wax mold on the base, and inspected under mi croscope (Altay, Turkey) with magnification power (X15).

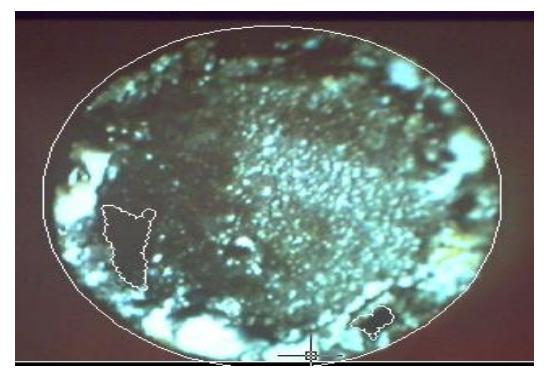

Figure (7): Auto CAD drawings on the cross section and around the porosities in the

fracture's photograph

RESULTS

The microscopic photographs of surface

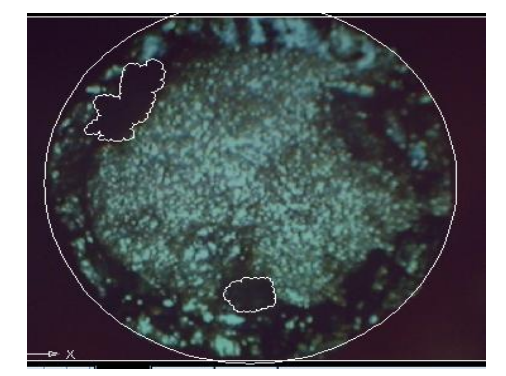

The pictures were captured in the computer using special digital camera connected via a wire to the computer, the saved fractographs were inspected for porosities and the discovered porosities' area were calculated using AutoCAD program, by drawing circular shapes around the sample's perimeter, and drawing cloud around the irregularly shaped porosity's area, and measure the area by finding the area of an object option available in the program, the percentage of the porosity's area to the cross section area were found to exclude the magnification factor, (Figure 7).

roughness test of the three treatment types were shown in Figure (8)
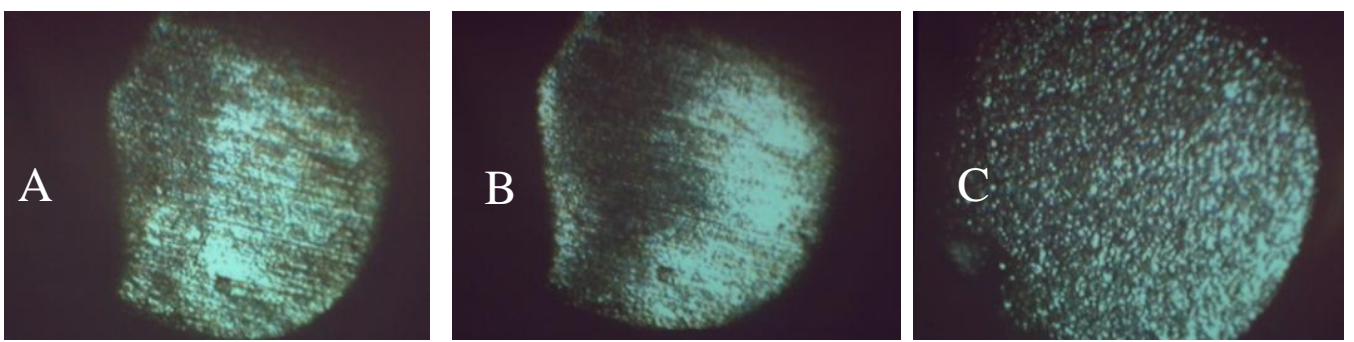

Figure (8): Microscopic view of the treated cross sections, A- Polished surface, B- Laser treated, C-Sandblasted surface

To find the difference in surface roughness between the three groups, one way ANOVA test was utilized (Table 1) and (Figure 9). 


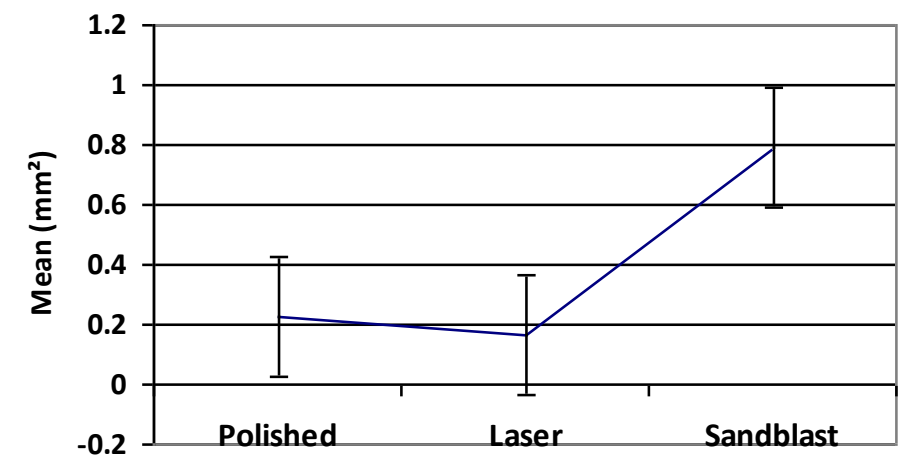

Figure (9): Surface roughness difference between groups.

Table (1): One way ANOVA test for the surface roughness

\begin{tabular}{cccccc}
\hline Source of variation & Sum of Squares & Df & Mean Square & F & Sig. \\
\hline Between Groups & .725 & 2 & .363 & 340.031 & .000 \\
Within Groups & .006 & 6 & .001 & & \\
Total & .732 & 8 & & & \\
\hline
\end{tabular}

The radiographic image of the control group showed no pores at all, while the laser welded group showed no porosity, but there was a lesser density area at welding zone area than the parental metal (Figure 10).

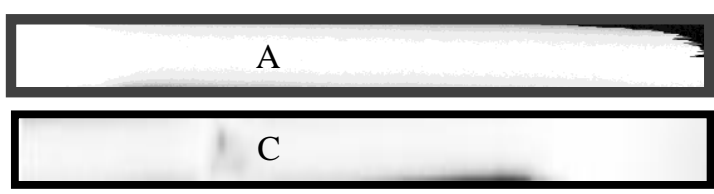

B

$\mathrm{D}$

$\mathrm{E}$

Figure (10): Radiographic images of the joints. A, control sample. B, laser welded joint. C, iron soldered joint. D, stainless steel soldered joint. E, brass soldered joint.

To find the difference in the porosities' areas in the stainless steel soldered joints were statistically analyzed using one way ANOVA, the results showed that there was no significant difference between the control group and the stainless steel soldered joints (Table 2).

Table (2): Descriptive analysis of the porosities in the X-ray images of the iron, stainless steel, and brass soldering

\begin{tabular}{cccccc}
\hline Groups & No. & Mean $\left(\mathrm{mm}^{2}\right)$ & SE & Minimum & Maximum \\
\hline Iron & 9 & 0.8596 & 0.31483 & 0.00 & 2.50 \\
Steel & 9 & 0.5953 & 0.28783 & 0.00 & 2.31 \\
Brass & 9 & 0.4691 & 0.43908 & 0.00 & 3.98 \\
Total & 27 & 0.6413 & 0.19863 & 0.00 & 3.98 \\
\hline
\end{tabular}

The Mean Ultimate Tensile Strength (UTS) of the Laser Welded Samples, mean difference, degree of freedom, and inde- pendent t-test results for equality of means for the ultimate tensile strength between the laser welded joints and the control 
group, found that there is significant difference between the UTS of the laser welded joints and the control group at $P<$ 0.05 (Table 3).

Table (3): Mean, mean difference, degree of freedom, and independent t- test results for equality of means for the ultimate tensile strength between the laser welded joints and the control group.

\begin{tabular}{rlllcccc}
\hline & Groups & $\mathbf{N}$ & Mean (MPa) & t & df & Sig. (2-tailed) & Mean Difference \\
\hline \multirow{2}{*}{ UTS } & Control & 3 & 886.6257 & \multirow{2}{*}{14.715} & \multirow{2}{*}{10} & .000 & 268.8392 \\
\cline { 2 - 4 } & Laser & 9 & 617.7864 & & & & \\
\hline
\end{tabular}

$\mathrm{df}$ : is the degree of freedom. $\mathrm{t}$ : t-test value $\mathrm{N}$ : number

The descriptive statistic of the UTS of the laser welded samples of the three sub- groups (Polished, laser treated, sandblasting) were listed in Table (4).

Table (4): Mean, standard error, minimum, and maximum limit of the ultimate tensile strength of the laser welded samples of the three subgroups.

\begin{tabular}{lccccc}
\hline Treatments & N & Mean (MPa) & SE & Minimum & Maximum \\
\hline Polished & 3 & 601.4930 & 5.91824 & 590.63 & 611.00 \\
Laser & 3 & 600.1357 & 8.25894 & 586.56 & 615.07 \\
Sandblast & 3 & 651.7307 & 2.35184 & 647.66 & 655.80 \\
\hline
\end{tabular}

SE: Standard of Error

To compare between the UTS of the three types of treatments joined by laser welding, ANOVA and Duncan's multiple range tests showed that the joints treated with sandblasting had significantly higher joints strength than the joints treated with polishing, and laser, which have no significant difference between them (Tables 5 and 6).

Table (5): One way ANOVA for the ultimate tensile strength of the laser welded samples between the three subgroups.

\begin{tabular}{lccccc}
\hline Source of variation & Sum of Squares & Df & Mean Square & F & Sig. \\
\hline Between Groups & 5187.710 & 2 & 2593.855 & 23.848 & .001 \\
Within Groups & 652.601 & 6 & 108.767 & & \\
Total & 5840.310 & 8 & & & \\
\hline
\end{tabular}

df: is the degree of freedom. F: F-test value.

Table (6): Duncan's multiple range test for the ultimate tensile strength of the subgroups joined by laser welding.

\begin{tabular}{lccc}
\hline Treatments & $\mathbf{N}$ & \multicolumn{2}{c}{ Subset for alpha $=. \mathbf{0 5}$} \\
\cline { 3 - 4 } Laser & 3 & 1 & 2 \\
Polished & 3 & 600.1357 & \\
Sandblasted & 3 & 601.4930 & 651.7307 \\
Sig. & & .879 & 1.000 \\
\hline
\end{tabular}

$\mathrm{N}$ : number

The mean, mean difference, degree of freedom, and independent t- test results for equality of means for the ultimate tensile strength (UTS) between the stainless steel soldered joints and the control group, found that there is no significant difference 
at $P=0.05$ (Table 7). The descriptive statistic of the ultimate tensile strength of the three types of treatments (Polished, laser treated, sandblasting) that were joined by stainless steel soldering were compared in between these types (Table 8).

Table (7): Mean, mean difference, degree of freedom, and independent t- test results for equality of means for the ultimate tensile strength between the stainless steel soldered joints and the

\begin{tabular}{llllcccc}
\hline Groups & $\mathbf{N}$ & $\begin{array}{c}\text { Mean } \\
\text { (MPa) }\end{array}$ & t & df & $\begin{array}{c}\text { Sig. (2- } \\
\text { tailed) }\end{array}$ & $\begin{array}{c}\text { Mean } \\
\text { difference }\end{array}$ \\
\hline \multirow{2}{*}{ UTS } & Control & 3 & 886.6257 & -.075 & 10 & .942 & -6.3360 \\
\cline { 2 - 4 } & Steel & 9 & 892.9617 & & &
\end{tabular}

df: is the degree of freedom. t: t-test value. UTS: is the ultimate tensile strength. N: number

Table (8): Descriptive statistic of the ultimate tensile strength of the stainless steel soldered samples of the three subgroups.

\begin{tabular}{lccccc}
\hline & N & Mean (MPa) & SE & Minimum & Maximum \\
\hline Sand & 3 & 1037.3383 & 14.17561 & 1014.26 & 1063.14 \\
Laser & 3 & 806.5167 & 10.96023 & 619.14 & 965.38 \\
Polish & 3 & 835.0300 & 16.46236 & 814.66 & 867.62 \\
\hline
\end{tabular}

SE: Standard of Error . N: number

One way ANOVA and Duncan's multiple range tests showed that the joints treated with sandblasting, had significantly higher joints strength than the joints treated with laser, and no significant dif- ference between polished joints' strength and sandblasted one. No significant difference found between the UTS of the polished joints' strength and the laser treated one (Tables 9 and 10).

Table (9): One way ANOVA for the ultimate tensile strength of the stainless steel soldered samples between the three subgroups.

\begin{tabular}{lccccc}
\hline Source of variation & Sum of Squares & df & Mean Square & F & Sig. \\
\hline Between Groups & 95020.314 & 2 & 47510.157 & 4.455 & .065 \\
Within Groups & 63989.557 & 6 & 10664.926 & & \\
Total & 159009.870 & 8 & & & \\
\hline
\end{tabular}

df: is the degree of freedom. F: F-test value.

Table (10): Duncan's multiple range test for the ultimate tensile strength of the subgroups joined by stainless steel soldering.

\begin{tabular}{llll}
\hline Treats & $\mathbf{N}$ & \multicolumn{2}{l}{ Subset for alpha $=.05$} \\
\cline { 3 - 4 } & & 1 & 2 \\
Laser & 3 & 806.5167 & 835.0300 \\
Polish & 3 & 835.0300 & 1037.3383 \\
Sand & 3 & & .053 \\
Sig. & & .747 &
\end{tabular}


The facture surfaces of the laser welded joints, and the control (nonrepaired joints) groups were tested by microscope, the image were treated by the AutoCAD computer program to calculate the area of the porosities present in the image of the three types of treated surfaces that repaired by laser welding. The descriptive statistic results of the Porosities of the laser welded joints and the control groups were listed in Table (11).

Table (11): Mean, standard error, minimum, and maximum limits of the results of the Porosities of the laser welded joints and the control groups.

\begin{tabular}{lccccc}
\hline & N & Mean (\%) & SE & Minimum & Maximum \\
\hline Control & 6 & 1.6842 & .68514 & .38 & 4.07 \\
LP & 6 & 7.5939 & .31380 & 6.18 & 8.32 \\
LL & 6 & 7.7835 & .31698 & 6.93 & 8.81 \\
LS & 6 & 6.1689 & 1.20657 & 2.78 & 10.49 \\
Total & 24 & 5.8076 & .61546 & .38 & 10.49 \\
\hline
\end{tabular}

LP: laser welded polished, LL: laser welded laser treated, LS: laser welded sandblasted .

One way ANOVA, and Duncan's multiple range tests found that there were significant difference between the three types of laser welded joints (Polished, laser treated, and sandblasted) and the control group, whereas there was no significant difference in between the three types (Tables 12 and 13).

Table (12): One way ANOVA test of the results of the Porosities of the laser welded joint.

\begin{tabular}{lccccc}
\hline Source of variation & Sum of Squares & Df & Mean Square & F & Sig. \\
\hline Between Groups & 145.367 & 3 & 48.456 & 15.208 & .000 \\
Within Groups & 63.725 & 20 & 3.186 & & \\
Total & 209.092 & 23 & & & \\
\hline
\end{tabular}

df: is the degree of freedom. F: F-test value.

Table (13): Duncan's multiple range test of the Porosities of the laser welded joint.

\begin{tabular}{lcccc}
\hline & Groups & $\mathbf{N}$ & \multicolumn{2}{c}{ Subset for alpha = .05 } \\
\cline { 3 - 5 } Duncan(a) & & 1 & 2 \\
& Control & 6 & 1.6842 & \\
LS & 6 & & 6.1689 \\
LP & 6 & & 7.5939 \\
LL & 6 & & 7.7835 \\
Sig. & & 1.000 & .153 \\
\hline
\end{tabular}

While the results of the facture surfaces of the stainless steel soldered joints, and the control (non-repaired joints) groups were listed in Table (14). 
Table (14): Mean, standard error, minimum, and maximum limit of the results of the Porosities of the stainless steel soldered joint.

\begin{tabular}{lccccc}
\hline & N & Mean (\%) & SE & Minimum & Maximum \\
\hline Control & 6 & 1.6842 & .68514 & .38 & 4.07 \\
SP & 6 & 4.9732 & .52042 & 2.06 & 9.03 \\
SL & 6 & 5.3538 & .57269 & 3.18 & 7.42 \\
SS & 6 & 4.2276 & .52530 & 1.87 & 5.57 \\
Total & 24 & 4.0597 & .47546 & .38 & 9.03 \\
\hline
\end{tabular}

SP: is polished joints soldered with stainless steel, SL: is laser treated joints soldered with stainless steel, SS: is sandblasted joints soldered with stainless steel.

Statistical analysis of the percentage of the porosities' areas were conducted using one way ANOVA, and Duncan's multiple range tests. The result found that there is significant difference between the three types of stainless steel soldered joints and the control group, whereas there was no significant difference in between the three types (Tables 15 and 16).

Table (15): One way ANOVA test of the results of the Porosities of the stainless steel soldered joint.

\begin{tabular}{lccccc}
\hline Source of variation & Sum of Squares & df & Mean Square & F & Sig. \\
\hline Between Groups & 49.082 & 3 & 16.361 & 4.322 & .017 \\
Within Groups & 75.704 & 20 & 3.785 & & \\
Total & 124.787 & 23 & & & \\
\hline
\end{tabular}

df: is the degree of freedom. F: F-test value.

Table (16): Duncan's multiple range test of the Porosities of the stainless steel soldered joint.

\begin{tabular}{lcccc} 
& Groups & $\mathbf{N}$ & \multicolumn{2}{c}{ Subset for alpha $=.05$} \\
\cline { 3 - 4 } Duncan(a) & Control & 6 & 1 & 2 \\
& SS & 6 & & \\
& SP & 6 & & 4.6842 \\
& SL & 6 & & 4.9732 \\
& Sig. & & 1.000 & 5.3538 \\
\end{tabular}

SP: is polished joints soldered with stainless steel, SL: is laser treated joints soldered with stainless steel, SS: is sandblasted joints soldered with stainless steel.

\section{DISCUSSION}

Radiographic Analysis of the Laser Welded Joints: Radiographic images of the samples joined by laser welding have shown a lower density area at the welding zone area. The radiographs showed radiotransparence in the fusion area, which indicates that the fusion is a superficial one and does not cover the entire thickness of the fused alloy. Although material plates are not very thick, welding does not cover the whole depth due to lack of penetration
(LOP) of the laser beam. This results in the fragility of the welding ${ }^{(12,13)}$

Radiographic Analysis of the Joints Joined with Stainless Steel Soldering: The mean value of the porosities' areas seen in the radiographic images of the joints soldered with stainless steel $(0.5953)$ $\mathrm{mm}^{2}$. Porosity is elongated and may appear to have a tail. This is the result of gas attempting to escape while the metal is still in a liquid state and is called wormhole porosity. ${ }^{(14)}$ 
UTS of the Laser Welded Joints: The average ultimate tensile strength of the Co$\mathrm{Cr}$ alloy ranged from (430 $\mathrm{MPa}$ to 1028 $\mathrm{MPa})^{(15)}$, in this study the average ultimate tensile strength of the control group was $(886.6257 \mathrm{MPa})$. The average tensile strength of laser-welded Co-Cr dental alloy joints investigated thus far has ranged from $404 \mathrm{MPa}$ to $751 \mathrm{MPa},{ }^{(7,11,16,17)}$ which is in agreement with the average strength of laser welds in this study of the three types of treatments (polished, laser treated, and sandblasted surfaces) (601.4930 MPa, 600.1357 MPa, 651.7307 $\mathrm{MPa}$ ) respectively. An important reason for that laser welds strength are weaker than that of the control group, in this study is a small effective cross-section of specimens that was actually joined. This is a problem associated with low weld penetration depth. . $^{(7,16)}$ Nevertheless, laser welding of Co-Cr denture frameworks has been used with considerable success in clinical practice. Results in this study showed that sandblasted joints joined with laser welding had significantly higher ultimate tensile strength than the other two types of treatment. This can be explained by lower reflection rate of the sandblasted surfaces which resulted in better absorption rate of the laser beam. Metals with a high reflection have a small degree of absorption in the visible and infrared spectral areas. Where, the reduced absorption of electropolished specimen appeared to be due to the high reflectivity of the smooth surface. ${ }^{(18,19)}$

UTS of the Soldered Joints: The average ultimate tensile strength of the soldered joints with stainless steel was with average ultimate tensile strengths of the brazed joints which ranged from (357 MPa to $792 \mathrm{MPa}) .{ }^{(11,17,20)}$

Relative to the native alloy, arc welding actually increased the samples' resistance to tensile loading. Thus, for arc welded joints, it is the acicular microstructure that must be at the origin of the variations in mechanical resistance observed. The extent and characteristics of the heataffected zone were dependent on the amount of heat transferred to the specimens. In this respect, brazing essentially increased the grains' size and altered their shape. Electron-beam welding augmented this phenomenon, yielding grains that encompassed the full diameter of the joint. This type of arrangement was correlated with highly tension-resistant joints. ${ }^{(21,22)}$

Effect of the Type of Treatment on the UTS of the Soldered Joints: The effect of the three treatments on stainless steel soldering, sandblasted surfaces had significantly higher ultimate tensile strength than the polished, and the laser treated surfaces which had no significant difference between their ultimate tensile strength. The energy levels applied caused the grains to fuse and dramatically increase in size, eventually encompassing the whole diameter of the joint. Supplementary metallographs showed that these hypersized grains. As this is true the surfaces treatments would have a pronounced effect on the surface texture of the alloy and it's grain size and configuration. Where the sandblasting results in increasing the surface roughness, and local plastic strain. ${ }^{(22)}$

Microscopic Area of Porosities:

Fracture surfaces of the laser welded joints showed that only peripheral aspects of these specimens were successfully joined. Under the surface there were large voids and a central un-welded area, which greatly diminished the effective crosssection of the joint. When the vapor pressure in the keyhole increases above a certain level, it may open a conduit at the bottom of the weld and the flow of gas can carry some liquid metal. As the laser beam moves forward, underfill may form if the molten metal cannot refill all the depressions at the bottom of the weld. ${ }^{(3)}$

Microscopic examination of the soldered joints fracture surfaces showed that there is significant difference between the control group's porosities' size and the soldered joints. These results are in agreement with the results of the SEM examination that revealed the fracture surfaces of brazed joints were relatively smooth, with some inclusions of the investment found by Zupančič et al. ${ }^{(17)}$

The results of Porosity's Formation of Surface Treatment showed that there was no significant effect of the treatment types on the pores formation of the stainless steel soldered, and laser welded fracture 
surfaces, although, the sandblasted surfaces had the lowest means of pore formation for all the joining groups, These results can be explained by sandblasting process effectively, remove or prevent the oxide layer formation that is present on the parent metal surfaces. During soldering, the parental metal surface should retain its non-oxidized status and absence of impurities in order to form a tight contact between the solder and the parental soldered surface. $^{(23)}$

\section{CONCLUSIONS}

Under the limitations of the current investigation this research concluded that the ultimate tensile strength of the laser welded was significantly lower than that of the stainless steel soldering. Sandblasted joints exhibited the highest means of ultimate tensile strength in all joining methods. Radiographic examination of laser welding showed radiotransparence in the fusion area, which indicates that the fusion is a superficial one and does not cover the entire thickness of the alloy. The other three types of soldering materials showed porous formation and air entrapment in the welding zone. Microscopic examination showed that laser welded joints had central un-welded area with central porosities. Microscopic examination of the arc welded joints showed that the stainless steel solders had the lowest pore percentage among the soldering materials.

\section{REFERENCES}

1. Graig R, Powers J. Restorative Dental Materials. $11^{\text {th }}$ Edition. Mosby Co., 2002; Pp 479-507.

2. Gapido CG, Kobayashi H, Miyakawa O, Kohno S. Fatigue resistance of cast occlusal rests using Co-Cr and Ag-Pd$\mathrm{Cu}-\mathrm{Au}$ alloys. J Prosthet Dent. 2003; 90:261-9.

3. Pastor M, Zhao H, Martukanitz RP, Debroy T. Porosity, underfill and magnesium loss during continuous wave Nd:Yag laser welding of Thin Plates of Aluminum Alloys 5182 and 5754. Welding Research Supplement. 1999; 207.S-216.S.
4. Hayes C. The abc's of nondestructive weld examination. NDTnet.1998; 3: 6

5. American Dental Association. Guide to Dental materials and Devices, 7 th Edition. Am Dent Assoc, Chicago. 1975; Pp 44-48, 209-211.

6. Hofstede TM, Ercoli C, Graser GN, Tallents RH, Moss ME, Zero DT. Influence of metal surface finishing on porcelain porosity and beam failure loads at the metal-ceramic interface. $J$ Prosthet Dent. 2000; 84: 309-317.

7. Bertrand C, PetitcorpsY, Albingre L, Dupuis V. Optimization of operator and physical parameters for laser welding of dental materials. Br Dent $J$. 2004; 196(7): 413-418.

8. American iron and steel institute (AISI). Welding of stainless steels and other joining methods. A designer's handbook series No 9 002. Distributed by Nickel development institute (2002).

9. HGIC (Home and Garden Information Center). Measuring the Area of a Home Lawn. The Clemson University Cooperative Extension Service. 2005; ttp://hgic.clemson.edu.

10. Finney RL, Thomas GB. Calculus. Addison-Wesley publishing company. 1990; Pp: 31-76.

11. Zupančič R, Legat A, Funduk N. Electrochemical and mechanical properties of cobalt-chromium dental alloy joints. Materiali in tehnologije / Materials and technology. 2007; 41(6): 295-300

12. Ardelean L, Bortun C, Sandu L. Nondestructive defectoscopic tests on laser welding points in partial denture alloy. European Cells and Materials. 2005; 10(1):15.

13. Srivastava SP, Unni TG, Pandarkar SP, Mahajan K, Suthar RL. Conventional radiography : a few challenging applications. Founder's day special issue, Barc newsletter. 2007; 285:174182.

14. Smith NJ. Radiographic testing of metal castings for use in dental implants. J Prosthet Dent. 1973; 30(3): 335-338.

15. Alvardo J, Maldonado R, Jorge Marxuach J, Otero R. Biomechanics of hip and knee prostheses Applications of 
Engineering Mechanics in Medicine. GED-University of Puerto Rico Mayaguez, 2003; Pp1-20.

16. Bertrand C, PetitcorpsY, Albingre L, Dupuis V. The laser welding technique applied to the non precious dental alloys procedure and results. $\mathrm{Br}$ Dent J. 2001; 190:255-257.

17. Zupančič R, Legat A, Funduk N. Tensile strength and corrosion resistance of brazed and laser-welded cobaltchromium alloy joints. $J$ Prosthet Dent. 2006; 96:273-282.

18. Miserendino LJ, Pick RM. Lasers in dentistry. $1^{\text {st }}$ edition, Quintessence publishing C, Inc.1995; Pp 27-38, 129-144, 145-160, 161-170, 231-245.

19. Zhao H, White DR, Debroy T. Current issues and problems in laser welding of automotive aluminium alloy. International Materials Reviews. 1999; 44(6): 238-266.
20. NaBadalung DP, Nicholls JI. Laser welding of a cobalt-chromium removable partial denture alloy. $J$ Prosthet Dent. 1998; 79: 285-290.

21. Wiskott HW, Macheret F, Bussy F, Belser UC. Mechanical and elemental characterization of solder joints and welds using a gold-palladium alloy. $J$ Prosthet Dent. 1997; 77: 607-616.

22. Wiskott H W, Doumas T, Scherrer SS, Susz C, Belser UC. Microstructures of Brazings and Welds Using Grade 2 Commercially Pure Titanium. Int $J$ Prosthodont. 2001; 14:40-47.

23. Lee SY, Lin CT, Wang MH, Tseng H, Huang HM, Dong DR, Pan LC, Shih YH. Effect of temperature and flux concentration on soldering of base metal. J Oral Rehabil. 2000; 27:10471053. 